\title{
EPILOGUE
}

\section{Indexical 'mismatch'; or, adaptability at work}

\author{
Jef Verschueren \\ University of Antwerp
}

\begin{abstract}
This epilogue reflects on the notions of 'irregularity' and 'mismatch' which form the leitmotiv for this issue on perspectivization in language use, and more specifically on perspective shift and perspective persistence. While endorsing the approach, it is suggested that, given the complexities involved (who orients to what aspects of context and how?) any stable form-function coding would probably fail to perform the communicative task at hand, so that adaptable structures and processes are predictable. It is also pointed out that the observed irregularities seem to show a high degree of persistence across time and space, and it is suggested that this 'regularity' may be the most useful focus for this type of research.
\end{abstract}

Keywords: perspective, form-function mapping, irregularity, mismatch, adaptability

Pragmatics, as the science of language use, must assume identifiable regularities in the relationship between linguistic forms and expressive and communicative functions. At the same time, pragmaticians know that form-function relationships are not stable: in actual language use they are, more often than not, quite negotiable. Not a single human language, maybe even a single utterance, represents a uni-interpretable code. There is nothing mysterious about this, nor is this a flaw in the design. It is simply a feature of linguistic adaptability, the natural outcome of evolutionary processes underlying the development of human language in the face of a task too complex for simple solutions (cf. Verschueren and Brisard 2002). Linguistic tools enabling us to cognitively master or categorize an infinite range of impressions and phenomena (say, lexical items), or to establish relationships between categorized 'entities' (say, grammar) are always and inevitably mere approximations of what they are aimed at. Hence the impressive variability between languages (cf. Verschueren forthc.). Similarly, the assumptions we make about what it is we need to say in order for our interlocutors to grasp what we 
'mean', or the imputations of intentionality we rely on to interpret what someone else is trying to communicate, are always hypothetical. Hence the multiinterpretability of utterances.

There is an interesting point of intersection between the moderately stable form-function relationship we must assume for a science of language use to be possible and the actual instability that must be taken into account and investigated whenever a pragmatician is at work. It is the point where the very form-function design in a language shows cracks under the pressure of the complex tasks it must serve. Though such cracks, mismatches, or form-function incongruities or irregularities have received quite a bit of attention, rarely attempts have been made to approach them as inevitable, or even essential, design features of language revealing underlying mechanisms which may themselves be of interest for an understanding of grammar as well as pragmatics.

One of those rare attempts is Francis and Michaelis (eds) (2003), Mismatch: Form-Function Incongruity and the Architecture of Grammar, which should be a standard reference to turn to for anyone interested in an account of how grammatical theories, from Minimalism and Government and Binding to Lexical Functional Grammar, Cognitive Grammar and Construction Grammar, deal with socalled mismatches. Francis and Michaelis distinguish complexity mismatches as in It seems that he likes it (in which the syntax contains more word-level elements - notably the initial it - than there are distinguishable elements in the semantics) ${ }^{1}$ from content mismatches (showing an incongruous mapping in the content of items from two different levels of representation) as in She seems to have left (a case of subject raising in which the subject of the main verb does not fit that verb semantically), Max is a cat (with the syntax of a transitive sentence but the semantics of an intransitive one), or You have apple on your shirt (which coerces the mass interpretation of a count noun). What all these cases share is that their interpretation as mismatches depends on a notion of default: "[...] mismatch cases in some sense violate an expected mapping in the language" (Francis and Michaelis 2003,22). In a contrastive perspective, this raises a very specific question: "How can we reconcile a language-internal notion of mismatch with crosslinguistic differences in mapping relationships?" (Francis and Michaelis 2003,14). Indeed, as any typologist will tell us, there are vast differences in the ways in which grammatical forms map onto functions. Thus, what can be regarded as 'irregular'

1. As pointed out to me by one of the reviewers of this paper, in other theoretical contexts for instance in Cognitive Grammar - the initial it does have meaning. This analysis, therefore, betrays a somewhat formalist background, in spite of its functional and pragmatic relevance, as will also be clear with some of the following examples. 
must be evaluated in a language-specific way. Yet, some general, if not universal, tendencies may be involved in the irregularities we find.

Against this background, the current issue of Pragmatics (Gentens et al. eds. 2019) makes a valuable contribution to an understanding of 'irregularities' in the architecture of natural languages as adaptive responses to semantic needs that do not fit simple and predictable structures. The authors have chosen the particularly intriguing field of perspective, i.e. the positioning of the 'conceptualizer' of an expressed meaning.

Just like the examples of mismatch given above, irregularity in perspectivization is measured against default cases of 'regular' perspectivizing constructions defined as expressions which (i) inherently refer to a pragmatically inferable conceptualizer, and which (ii) make use of grammatical and lexical elements dedicated to the encoding of perspectival meaning. A standard case would be John said "I will be late", where the transparent shift in perspective from the current speaker to the reported speaker John (i.e. criterion (i)) is matched by the construction (third person vs. first person, past vs. future, punctuation; i.e. criterion (ii)). Irregularities are then defined as cases in which there is a mismatch between the conceptualizer signaled 'by default' by a construction and the referential entity interpreted as conceptualizer in the context of use. Given part (ii) of the definition, also the issue of cross-linguistic differences cannot be avoided, and receives appropriate attention.

Perspective or perspectivization is one dimension of contextual indexing, the establishment of links between utterances and context. While contextual indexing is always a matter of language users' selective orientation to specific aspects of the essentially infinite blur of potentially relevant stuff 'out there' (reflected in explicit wording as well as in various layers of pragmatically inferable implicit meaning), perspective or perspectivization is a matter of who does the orienting and how (the to what being shared with indexing in general). Contextual indexing is always intersubjectively achieved. But it is not just a matter of interaction between utterer/speaker and interpreter/hearer. Clearly, the 'who'-range of perspectivization is not restricted to utterer and interpreter; also third parties' perspectives may be represented. As with almost everything else in language, ascribing expressed content to a particular 'conceptualizer' can be done explicitly (e.g. with clear person deixis) as well as implicitly. How this may lead to vagueness or possible ambiguity is nicely illustrated in this issue with reference to literary examples by Lieven Vandelanotte ("Changing Perspectives: Something Old, Something New") as well as by Max van Duijn and Arie Verhagen ("Recursive Embedding of Viewpoints, Irregularity, and the Role for a Flexible Framework"). The 'how'-range of this triadic (or multiplex) orientation to context involves all shades of modality (epistemic as well as deontic), evidentiality, even evaluation and deference. It is not 
surprising, therefore, that all contributions to this issue are confronted with complexity, whether or not the authors emphasize this point.

As already mentioned, the focus of this issue is on irregularities, as measured against the above definition of 'regular' perspectivizing constructions, in particular cases of perspective shift (with a shift in the interpretive assignment of a conceptualizer in spite of the formal maintenance of a point of view, as in indirect reported speech of the type John said he would be late), and cases of perspective persistence (with a formal shift which does not change the conceptualizer, as in non-quotational quotations of the type These flowers say "reckless" or "thoughtless"). It is not the intention to recapitulate arguments and observations in this epilogue. I just want to re-emphasize what I see as the main line of analysis running through the papers, and I will conclude with a general thought which this type of research seems to bring into focus.

The overall orientation towards complexity is not only based on unexpected forms of shift and persistence. Perhaps it follows first and foremost from the fact that on many occasions there are multiple perspectives involved simultaneously which, according to van Duijn and Verhagen, are interlinked in ways that cannot be reduced to neat embeddings. Van Duijn and Verhagen invoke the notion of 'thoughtscapes' to account for this, an idea that is reminiscent of Fauconnier's (1985) mental spaces, which also allow for various kinds of blending. Looking at the different papers, it is clear that similar phenomena pop up in many different places at many different times. Vandelanotte draws a line from free indirect speech in canonical literary texts to non-quotative uses of direct speech in internet memes (e.g. "I love your crocs"- said no one ever). Aung Si and Stef Spronck ("Solega Defenestration: Underspecified Perspective Shift in an Unwritten Dravidian Language") show that free indirect speech is not an exclusive property of western high literature but that it occurs in spoken interaction as well in the completely oral speech community they are investigating. Sonja Zeman ("The Emergence of Viewpoints in Multiple Perspective Constructions") illustrates the persistence of comparable perspective constructions (in particular the 'future of fate' construction, as in He was never to return) over more than two millennia in very different cultural environments, from Homeric Greek to present-day German. Similarly, Sergeiy Sandler and Esther Pascual ("In the Beginning There Was Conversation: Fictive Direct Speech in the Hebrew Bible") adduce occurrences in the Hebrew Bible of non-quotational direct speech expressing mental states introduced by the infinitival form of a verb of saying, grammaticalized into a complementizer. Thus, linguistically, the bible is closer to the internet than one might expect.

This leads me to a concluding observation: there seems to be a striking degree of regularity in the so-called irregularities. 
Francis and Michaelis start the introduction to their book with reference to evolutionary biology which has pointed out mismatches "requiring organisms to use suboptimal traits as effectively as possible to deal with new stimuli" (Francis and Michaelis 2003,1). They adduce the example of amphibians leaving water 250 million years ago, probably because aquatic life was more competitive than terrestrial life. Amphibians failed to become completely independent of water because of their porous skin serving them well underwater but leading to quick dehydration on land. They survived nonetheless because the same skin produced secretions acting as predator repellents. As if it is just a detail, they note in passing

Although the association between a linguistic form and its semiotic function cannot be said to be suboptimal in the same way that porous skin is for a land animal, form-function mappings may nonetheless be incongruent with respect to more general patterns of correspondence in the language.

(Francis and Michaelis 2003,2)

Maybe this is a point to be stressed rather than to be passed over furtively. What is happening with language at the level of what can be seen as mismatches or irregularities may not be suboptimal by a long stretch. Francis and Michaelis may very well agree with that. Certainly, they could have drawn precisely that conclusion after ending the same introduction to their book with reference to Dwight Bolinger's observation that the demands of verbal communication are such that speakers must adapt routines as needed (Bolinger 1976), and to Claude LévyStrauss's suggestion that (linguistic) tools are adaptive responses to (communicative) needs while their availability also shapes new (communicative) purposes (Lèvi-Strauss 1966). My own position on these issues, taking into account linguistic variability in the face of a virtually infinite range of potentially relevant meanings to be expressed, is to define language, or any specific language, as $a$ conglomerate of sedimented realization patterns of meaning potential, where such sedimented realization patterns provide further usage potential: not only can the patterns differ (leading to differences in affordance for concrete realizations of potential, and enabling us to make contrastive observations across language communities), but once available, patterns lead to varying forms of usage (i.e. divergent realizations of pattern-specific affordances) (see Verschueren 2018).

Given the many contextual dimensions that are involved in assessing who does the orienting to what aspects of context and how, in a given utterance, it would be extremely surprising if languages would have structural markings available for the full range of complex perspectives involved. Just like optionality, the use and non-use of linguistic elements, is seen by McGregor (2013) as susceptible to testable generalizations, we may have to learn to look at irregularity as an 
essential design feature of language. Si and Spronck are on the right track when using McGregor's insights.

Using terms such as mismatch or irregularity makes sense if, as is done in this issue, we regard as irregular whatever happens in spite of the availability of coding devices that may lead you to expect something else. But the question is: Whose expectations are involved? Does a language user expect fixed form-function mappings? Or are we, linguists, conveniently inclined to define them as the norm? We may of course do so, but only for heuristic purposes. As all other areas of meaning generation, perspective and perspectivization are subject to the constant calibration that takes place in language use between what is said explicitly and what is meant and understood. This is precisely what makes human language the powerful tool that it is. There is nothing suboptimal about it. From that point of view, the type of research reported in this issue can be seen unambiguously as oriented in the direction of generalizable phenomena and processes within the realm of unpredictability - a commendable line of work to be continued.

\section{References}

Bolinger, Dwight. 1976. "Meaning and Memory." Forum Linguisticum 1: 1-14.

Fauconnier, Gilles. 1985. Mental Spaces: Aspects of Meaning Construction in Natural Language. Cambridge, Mass.: MIT Press.

Francis, Elaine J., and Laura A. Michaelis (eds). 2003. Mismatch: Form-Function Incongruity and the Architecture of Grammar. Stanford: CSLI Publications.

Gentens, Caroline, Maria Sol Sansiñena, Stef Spronck, and An Van linden (eds). 2019. Irregular Perspective Shifts and Perspective Persistence: Discourse-Oriented and Theoretical Approaches. Special issue of Pragmatics 29:2.

Lévi-Strauss, Claude. 1966. The Savage Mind. Chicago: University of Chicago Press.

McGregor, William B. 2013. “Optionality in Grammar and Language Use.” Linguistics 51(6): 1147-1204. https://doi.org/10.1515/ling-2013-0047

Verschueren, Jef. 2018. “Adaptability and Meaning Potential.” In The Dynamics of Language: Plenary and Focus Papers from the 2oth International Congress of Linguists, Cape Town, July 2018, ed. by Rajend Mesthrie, and David Bradley, 93-109. Cape Town: UCT Press.

Verschueren, Jef. Forthc. "Diversity, Linguistic." In The International Encyclopedia of Linguistic Anthropology, ed. by James Stanlaw. Hoboken, NJ: John Wiley \& Sons.

Verschueren, Jef, and Frank Brisard. 2002. “Adaptability.” In Handbook of Pragmatics, ed. by Jan-Ola Östman \& Jef Verschueren, 1-24. Amsterdam: John Benjamins. Available online at https://benjamins.com/online/hop. https://doi.org/10.1075/hop.6 


\section{Address for correspondence}

Jef Verschueren

Universiteit Antwerpen

Taalkunde

Prinsstraat 13

Antwerpen, 2000

BELGIUM

jef.verschueren@uantwerpen.be

\section{Biographical notes}

Jef Verschueren received a Ph.D. in Linguistics from the University of California at Berkeley. After a long career as a researcher for the Flemish Fund for Scientific Research, and as Professor of Linguistics at the University of Antwerp, Belgium, where he served as Dean of the Faculty of Arts from 2001 to 2009, he is now Professor Emeritus. He is the founder and Secretary General of the International Pragmatics Association (IPrA; https://pragmatics.international). Main interests are theory formation in linguistic pragmatics (conceived broadly as a cognitive, social, and cultural perspective on language and language use), intercultural and international communication, and language and ideology. Some recent publications include the annually updated Handbook of Pragmatics (Amsterdam/Philadelphia: John Benjamins; first published in 1995, coedited with Jan-Ola Östman, now also available online), Debating Diversity: Analysing the Discourse of Tolerance (London: Routledge, 1998; co-authored with Jan Blommaert), Understanding Pragmatics (London: Edward Arnold / New York: Oxford University Press, 1999; now freely downloadable at https://repository.uantwerpen.be/docman/irua/o3eb7o/20735.pdf), Ideology in Language Use: Pragmatic Guidelines for Empirical Research (Cambridge University Press, 2012).

https://orcid.org/oooo-0002-4120-9068

\section{Publication history}

Date received: 25 February 2019

Date accepted: 20 March 2019 